\title{
Ontología y epistemología en la filosofía latinoamericana de Alejandro Serrano Caldera como fundamento de la Cultura de Paz
}

“América Latina tiene y ha tenido filosofía. No las imitaciones ni la mala copia de los griegos, los alemanes y los franceses, sino el pensamiento que ha buscado la identidad del hombre americano en el laberinto de su propia historia y a partir de su situación particular". Alejandro Serrano Caldera El derecho a la esperanza de Andrés Pérez Baltodano

\section{Resumen}

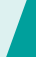

Anastasio Lovo en este texto, dimensiona y destaca los elementos de una estructura profunda de sentido -ontológica y epistémica- en la filosofía latinoamericana del Maestro Alejandro Serrano Caldera.

Para el autor, la filosofía de Serrano Caldera también contiene una valiosa y pertinente indagación de nuestro ser latinoamericano y sus formas de sentir, conocer, reflexionar y expresarse, que proporciona una valiosa veta teórica y práctica para fundamentar una cultura de paz desde América Latina para el mundo.

El pensamiento filosófico de Alejandro Serrano Caldera, marca aquellos desafíos vividos en la historia latinoamericana, como proceso dialéctico de construcción de un ser particular y al mismo tiempo, universal.

Palabras clave: Obra, ontología, filosofía, análisis dialéctico, razón.

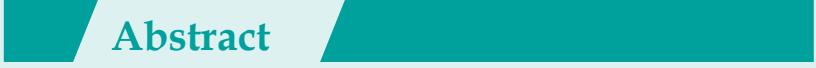

Anastasio Lovo in this text, dimensions and highlights the elements of a deep structure of sense - ontological and epistemic - in Latin American philosophy of Master Alejandro Serrano Caldera.

For the author, the philosophy of Serrano Caldera also contains a valuable and pertinent inquiry of our Latin American being and his ways of feeling, knowing, reflecting and expressing, which provides a valuable theoretical and practical vein, which are the foundation for a culture of peace from Latin America to the world.

The philosophical thought of Alejandro Serrano Caldera, marks those challenges experienced in Latin American history, as a dialectical process of building of a particular being and at the same time universal.

Key words: work, ontology, philosophy, dialectical analysis, reason.

1 Conferencia magistral dictada en el marco de la VI Cátedra "Alejandro Serrano Caldera", organizada por la Escuela de Ciencias Jurídicas y Políticas de la UPOLI. Managua, 27 de septiembre de 2016.

2 Poeta y escritor nicaragüense. Presidente Honorario del Centro Nicaragüense de Escritores (CNE). 


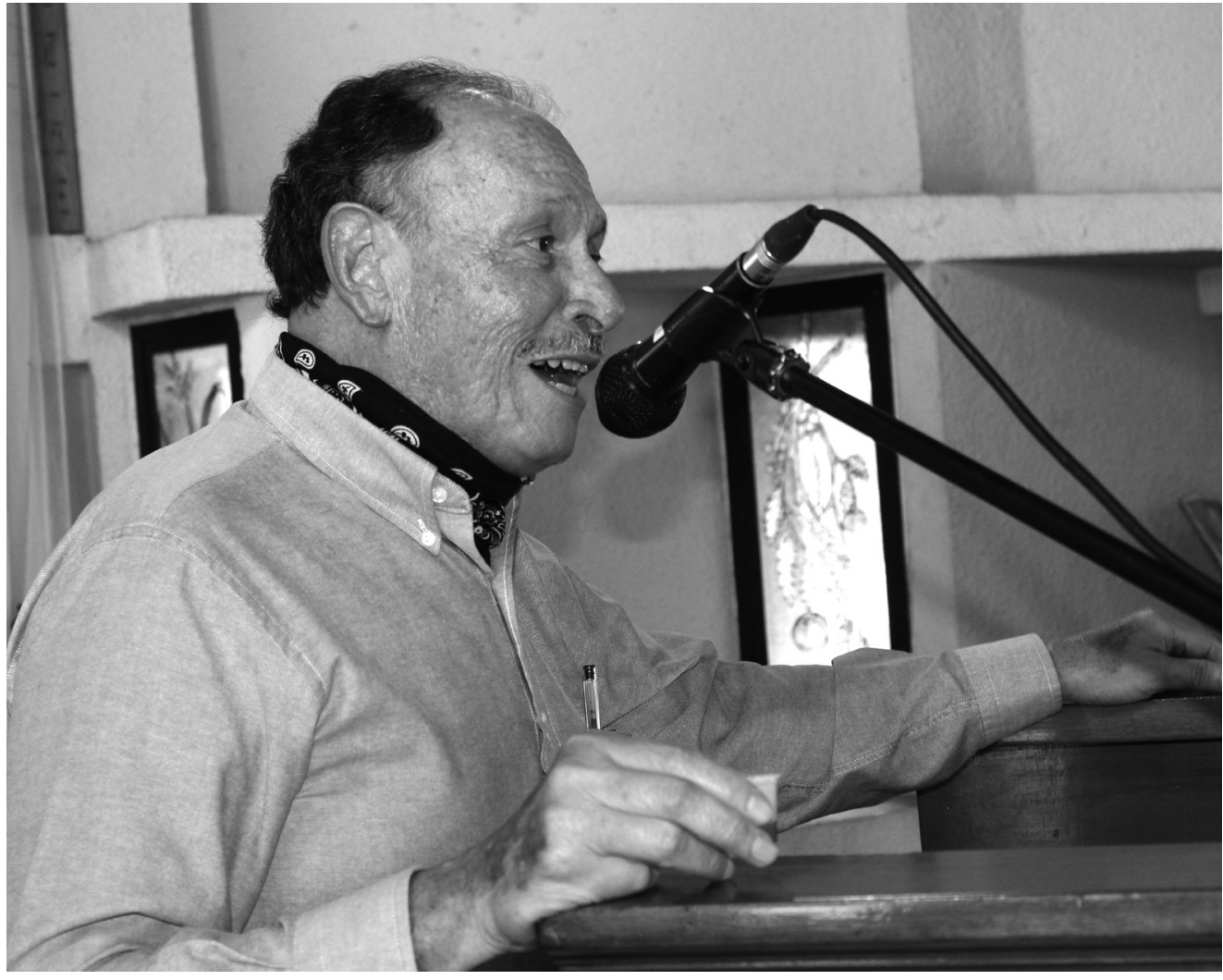

Profesor Anastasio Lovo dictando conferencia magistral. Foto: R. Públicas UPOLI.

Alejandro Serrano Caldera (Masaya, 1938) es el filósofo nicaragüense por excelencia y uno de los pensadores latinoamericanos que ha realizado imprescindibles aportes para sistematizar una filosofía identitaria de nuestra región capaz de contener en su corpus: una ontología, una epistemología, una axiología y una ética política, que sin perder de vista la problemática del ser universal, sugieran vías de acceso plausibles e interesantes para intentar responder las interrogantes del ser latinoamericano a partir de su realidad histórica, material y espiritual.

Alejandro Serrano Caldera sintetiza, compendia y enriquece al pensamiento de la filosofía latinoamericana, utilizando el método de análisis dialéctico que va de lo particular a lo general y de lo concreto a lo abstracto; y viceversa, es decir, despliega ambas vías de apropiación de conocimiento. Para realizar la hazaña de su sobresaliente labor filosófica, ASC utiliza el racionalismo europeo, la dialéctica hegeliana, la deconstrucción nietszcheana, la filosofía latinoamericana de la liberación, la crítica al pensamiento postmoderno y la ensayística creativa literaria de nuestro continente.
La valiosa contribución filosófica de Alejandro Serrano Caldera se encuentra contenida en cinco volúmenes, por el momento, bajo el título de Obras. Para fines de este ensayo de imaginación crítica, en las citas me referiré entonces a Alejandro Serrano Caldera: Obras Volumen III América Latina ante la razón filosófic Escritos sobre el pensamiento, la política y la cultura nicaragüense, Edición de Pablo Kraudy, Publicada por CNU-AECIDHispamer, Managua, 2011. (Serrano 2011).

En los cimientos de su fundamentación racional sobre el ser latinoamericano, Serrano Caldera postula que este ser se encuentra históricamente tensionado (ontológica y epistemológicamente)entre la razón y la intuición. Ser y conocer son conceptos dialécticos, próximos y me atrevería a afirmar, hasta simbióticos en la obra del Maestro Alejandro Serrano Caldera. La dialéctica entre el ser y el conocer, fundamental en la ontología epistémica de Serrano Caldera, se resuelve en una síntesis metodológica superior que él enuncia como unidad de contrarios: El ser es el conocer y quien conoce es. Suprema letio!

\section{Cito al Maestro Serrano:}

Un rasgo común, sin embargo, excepción hecha de los sectores ilustrados de las grandes civilizaciones indígenas, fue la visión mágica del mundo y la deificación de la naturaleza. Su teogonía naturalista conllevaba no sólo una visión intuitiva, que puede llegar a ser un grado altamente desarrollado de percepción de la realidad, sino una visión mítica y simbólica del mundo y de la vida de carácter más bien primitivo, de la que estaba excluida una intuición desarrollada y una conducta racional y crítica". (§ 6, p. 153, 3. Entre la intuición y la razón, NI). Supongo que este ensayo pertenece al libro Entre 
la Nación y el imperio de Serrano Caldera escrito en 1988. No deja de llamar la atención la afirmación de Serrano sobre esa "visión mítica y simbólica del mundo y de la vida de carácter más bien primitivo, de la que estaba excluida una intuición desarrollada y una conducta racional y crítica."

Frente a esta afirmación debo confesar que la percibo como una lectura o visión, pre-levistraussiana, específicamente en el sentido de soslayar las conclusiones de Claude Lévi Strauss en El pensamiento salvaje cuando sostiene que:

El pensamiento mágico no es un comienzo, un esbozo, una iniciación, la parte de un todo que todavía no se ha realizado; forma un sistema bien articulado, independiente, en relación con esto, de ese otro sistema que constituirá la ciencia, salvo la analogía formal que las emparienta y que hace del primero una suerte de expresión metafórica de la segunda. Por tanto, en vez de oponer magia y ciencia, sería mejor colocarlas paralelamente, como dos modos de conocimiento, desiguales en cuanto a los resultados teóricos y prácticos (pues de este punto de vista, es verdad que la ciencia tiene más éxito que la magia, aunque la magia prefigure a la ciencia en el sentido de que también ella acierta algunas veces), pero no por la clase de operaciones mentales que ambas suponen, y que difieren menos en cuanto a la naturaleza que en función de las clases de fenómenos a las que se aplican." (Levi Strauss 1962).

Indudablemente el mundo mítico y la manera de conocer de las grandes civilizaciones originarias precolombinas- no se fundamentaban en el racionalismo europeo, pero tampoco su manera de producir conocimiento y pensamiento estaba alejada de poderosas racionalizaciones taxonómicas, de un apego analógico y homeopático a la realidad natural, ni de una imaginación que daba cuenta del mundo de una manera intuitiva y creativa.

Las culturas originarias de Abbya Yala se encontraban en crisis al momento de la llegada de los europeos. A esa crisis natural del desarrollo de aquellas civilizaciones, hay que añadirle el impacto, el trauma, la herida que provoca el choque entre las culturas originarias y las europeas.

Serrano Caldera la analiza así para marcar la carencia de síntesis en la cultura latinoamericana desde sus orígenes hasta nuestros días:

La alteración del desarrollo sea biológico, psicológico o social, no se produce sin consecuencias. La alteración de las sociedades indígenas por la conquista y la colonia, produjo atrofia e hipertrofia. Por una parte, posibilidades históricas que no llegaron a realizarse, y por otra, expresiones desmesuradas que no guardan armonía con lo que exige la realidad ni con el futuro posible. La profundización y transmisión de una cultura indígena que históricamente la hiciera expresarse como vivencia y no como folklore y arqueología, no se dio por la ruptura que ocasionó la colonia. Tampoco se produjo, y no se ha producido aún, la síntesis histórica". (\$ 3, p. 154, 3. Entre la intuición y la razón, NI).

Además de la fractura histórica a-sintética, nuestro filósofo postula una superposición/ yuxtaposición de culturas como sustrato ontológico originario del ser latinoamericano:

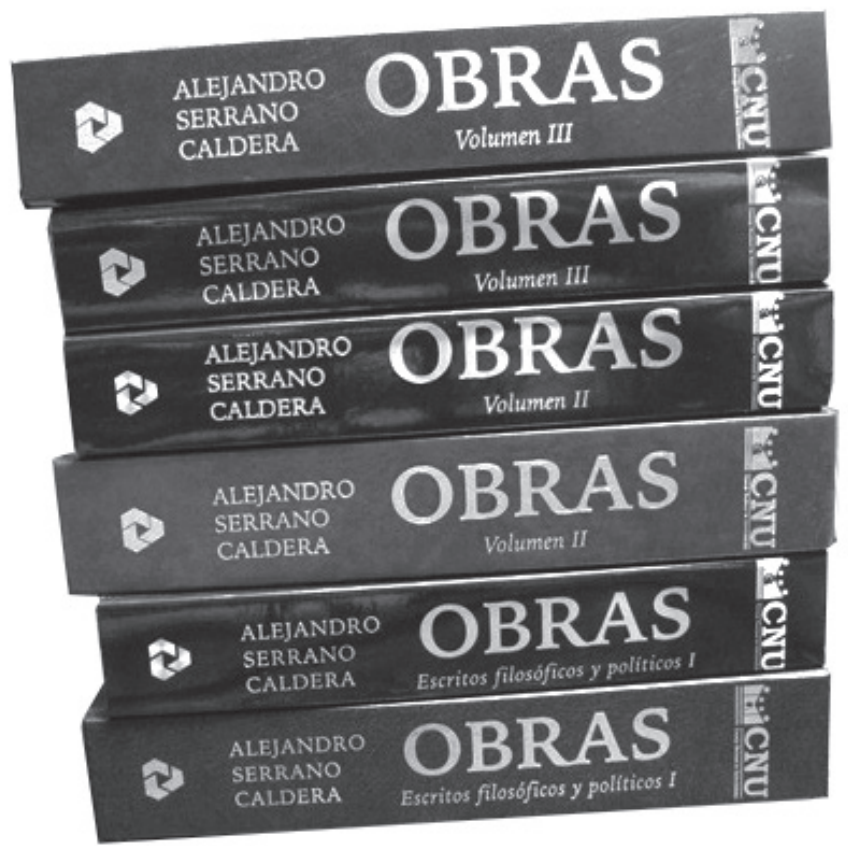

Fuente: Foro Nicaragüense de Cultura (FNC). 


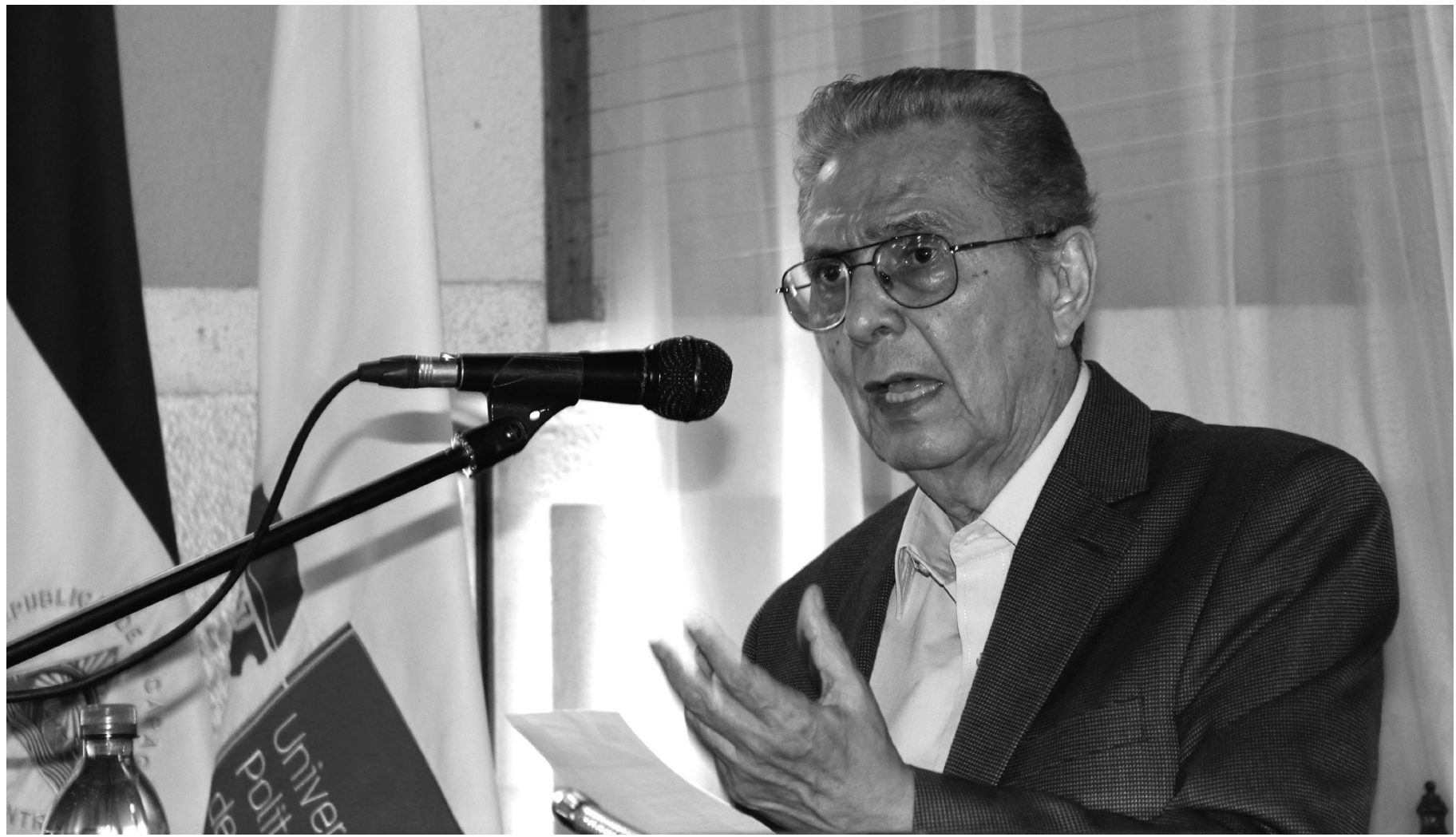

Dr. Alejandro Serrano Caldera, filósofo nicaragüense. Foto: R. Públicas UPOLI.

La fractura histórica que produjo la colonia superpuso un tipo de sociedad, la dominante española, a otra, la dominada indígena; pervivió, sin embargo, de lo indígena (bajo las nuevas creencias, idiomas, formas sociales y plexo de valores) la concepción mítica del mundo. Una captación mágica que emergió desde el subsuelo de la historia, vino a dominar la psicología individual y colectiva de nuestros hombres y pueblos. Junto a esto, una percepción intuitiva primaria y una captación espontánea de la realidad parecieran conformar nuestra relación con la vida natural y social. (§ 5, p. 154, 3. Entre la intuición y la razón, NI).

Frente a esa superposición de culturas y en ausencia de síntesis cultural, Serrano concibe el desarrollo del ser latinoamericano de una manera creativa, cercana al pensamiento filosófico que se ha generado en nuestro continente. Escribe Serrano:
La formación del ser latinoamericano está profundamente unida a la constitución y desarrollo de su filosofía, así como la formación de esta última está indisolublemente ligada al destino de nuestro ser. No se trata de que el ser latinoamericano sea producto de un cierto tipo de elucubración racional, sino de la contribución que la filosofía, en tanto pensamiento esclarecido, puede aportar en esta búsqueda de identidad." (§4, p.141, 2. Prolegómenos a una teoría del ser latinoamericano, ENI).

Después Serrano Caldera da cuenta de la rica realidad latinoamericana hasta elevarla como un elemento ontológico constitutivo del ser latinoamericano en el desafío epistémico, ético y político de su tarea liberadora. Veamos esta cita:

Pero la búsqueda y encuentro de ese ser se produce sobre todo en la realidad multiforme y contradictoria en la cual el hombre vive y sobrevive. La liberación es la condición 


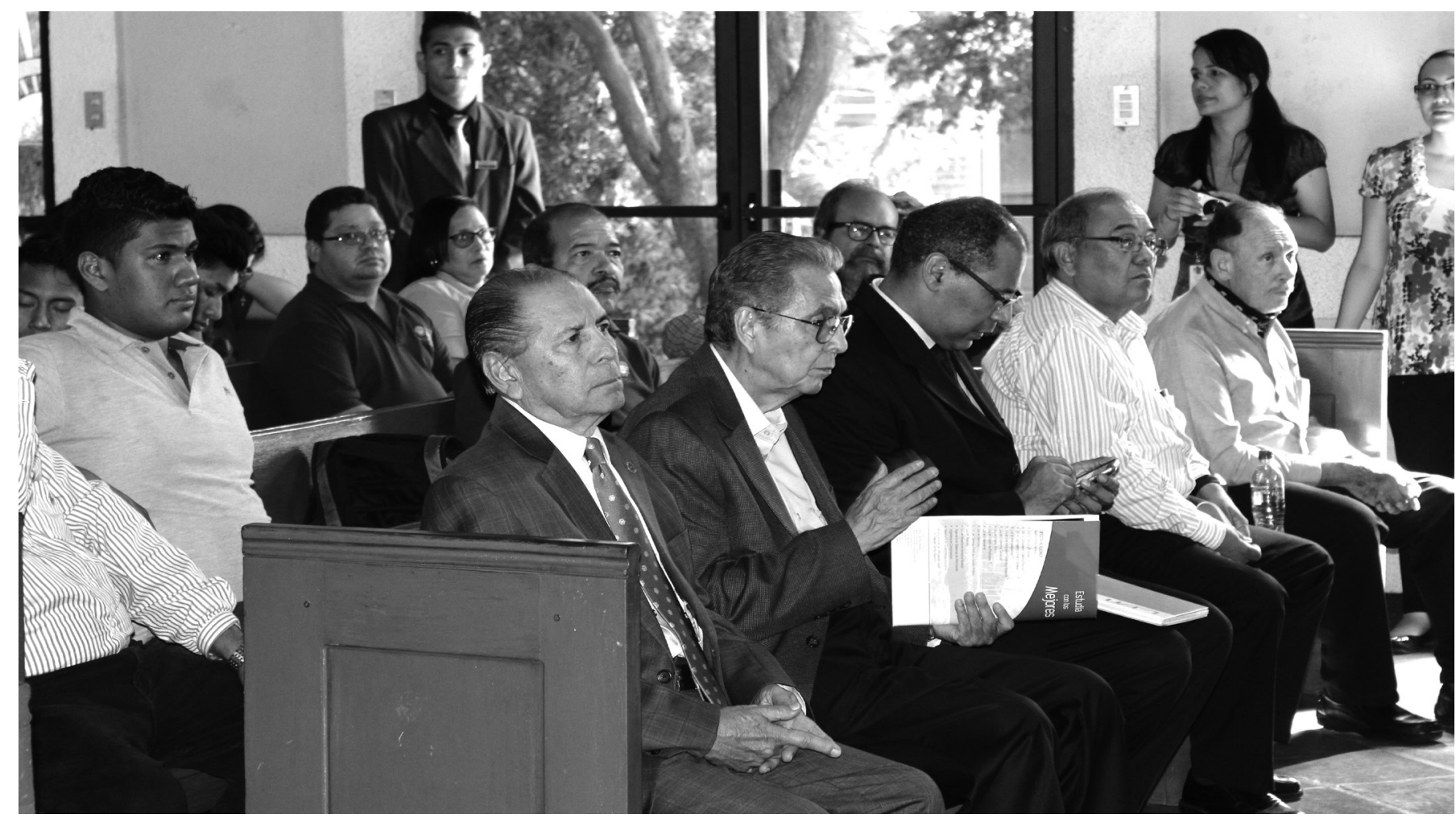

R. Públicas UPOLI.

histórica del ser latinoamericano. Liberación que se expresa en la posibilidad de reafirmar lo propio, en la capacidad de creación. (§ 3, p. 142, 2. Prolegómenos a una teoría del ser latinoamericano, ENI).

Es aquí donde la filosofía en Alejandro Serrano Caldera se nos revela como bella y única en su pertinencia, al introducir un concepto dialéctico, útil y oportuno, que perfectamente puede dar cuenta de la realidad cultural de América Latina pero también del resto del planeta, el concepto de unidad en la diversidad: "Si América Latina debe ser una unidad de diversidades, cada una de estas diferencias debe partir, precisamente, de todo aquello que consolida y fortalece una realidad nacional."(\$1, p.43, 2. Prolegómenos a una teoría del ser latinoamericano, ENI).

Pero esta unidad de diversidades que constituyen a América Latina, según Alejandro Serrano Caldera y nuestra experiencia histórica, fue, es y será negada por el colonialismo, el neocolonialismo y el imperialismo. Aunque esta lucha política, geopolítica y cultural ha devenido en dínamo y acumulador de identidad para nuestro continente. Cito al Maestro Serrano: "Si el colonialismo y el imperialismo constituyen la causa fundamental de negación de la nación, la lucha contra ellos es la reafirmación primaria de la nación y la expresión más fuerte de identidad." (\$4, p. 143, 2. Prolegómenos a una teoría del ser latinoamericano, ENI)

Sobre la relación entre libertad conquistada e identidad construyéndose en los procesos de independencia de América Latina, nuestro filósofo nos dice: "Los movimientos liberadores que nos da la independencia no llegan a darnos, sin embargo, identidad. La libertad no es la identidad, aunque es condición necesaria de su existencia."(§ 4, p. 144, 2. Prolegómenos a una teoría del ser latinoamericano, ENI).

Pese a haber conquistado una cierta libertad frente a los poderes metropolitanos, la tentación de adoptar corrientes de pensamiento foráneas (europeas y norteamericanas) de manera acrítica, nos ha impedido lograr -según ASC- una síntesis histórica que nos posibilite superar el pasado y construir nuestro futuro: Cito:

Sin embargo, la situación general ha sido la de transferir de manera a-crítica las corrientes de 
pensamiento predominantes en Europa. Sigue entonces sin realizarse la síntesis histórica que permita superar dialécticamente el pasado y construir a partir de ahí nuestra identidad, que es el inicio de la construcción del futuro. Todavía seguimos atrapados en las redes del pasado, porque nuestra actitud, sea de rechazo o de aceptación de lo europeo, ha sido en ambos casos igualmente acrítica." (§ 5, p. 145, 2. Prolegómenos a una teoría del ser latinoamericano, ENI).

Además del a-criticismo de los latinoamericanos frente al pensamiento europeo, Serrano señala que hay tareas no realizadas o postergadas:

Nosotros somos herederos de lo que hicieron, pero sobre todo de lo que no hicieron o no pudieron hacer los hombres del siglo XIX. $\mathrm{Si}$ no lo logramos ahora, heredaremos a los latinoamericanos del siglo XXI la inmensa carga de realizar la síntesis histórica que no se hizo ni en el siglo XIX ni en el XX. (§ 5, p. 146, 2. Prolegómenos a una teoría del ser latinoamericano, ENI).

En el ámbito de la relación epistemologíaontología Serrano distingue los aportes de productos de la creación, como el arte, la filosofía y las ciencias, a los problemas de identidad y de conocimiento del ser latinoamericano:

Sin embargo, ni la literatura ni la pintura por sí solas, pese a su excelencia, podrán otorgarnos la identidad que buscamos, pues por su naturaleza misma en América Latina, o son expresiones descriptivas de la realidad, o ficciones, o símbolos, que o bien traducen la realidad tal como ésta es, o crean ilusiones que permitan evadirla, pero no pueden transformarla al grado que la búsqueda de la identidad lo exige. Es a partir de la transformación de la propia realidad histórica y del pensamiento crítico en donde deberá estructurarse la identidad latinoamericana. (\$3, p. 147, 2. Prolegómenos a una teoría del ser latinoamericano, ENI).

Tanto la filosofía como las ciencias sociales han contribuido a crear una conciencia acerca del problema de la autenticidad. La filosofía ha esclarecido mucho sobre el ser y el no ser latinoamericano. La lucha por la identidad es un desafío que envolverá la lucha política, la vida cotidiana, el esfuerzo intelectual, el aporte multisectorial de las disciplinas filosóficas, la imaginación y la creación artísticas." (§ 2, p. 148, 2. Prolegómenos a una teoría del ser latinoamericano, ENI.

Podemos diferir de las valiosas lecturas que hace Serrano Caldera sobre nuestro ser latinoamericano, su ontología y su epistemología. Podemos alegar que el arte, los aportes científicos, la misma filosofía de la liberación y el mismo pensamiento de Alejandro Serrano Caldera son productos emblemáticos de la síntesis cultural que hemos logrado los latinoamericanos. Por supuesto hay sociedades donde la superposición de culturas es más evidentes como en el Perú o Guatemala, el mismo México y la mismísima cuenca de la Amazonía donde más que yuxtaposición hay una interconexión simbiótica transcultural. Y para este tipo de sociedades, el aserto de la superposición es una realidad.

Si tomamos a América Latina como conjunto, podríamos hablar de su interconectividad económica como sociedades que pueden ser analizadas y caracterizadas por la ley del desarrollo desigual combinado y sin combinar. Y distinguiría sociedades más o menos integradas vía mestizaje y sociedades de la superoposición étnico-cultural. El mestizaje, por razones de economía lingüística, lo entendiendo como la mezcla entre dos o más etnias y sus respectivas culturas.

El lenguaje, la cocina, la música, la religiosidad, la festividad y otros elementos, constituyen poderosas señas de una identidad latinoamericana en construcción que han impactado en otras culturas. La gran literatura latinoamericana, la cocina mexicana, peruana, brasileira, caribeña, el mambo, el chachachá, la salsa, la samba, el tango, entre otros, la religiosidad popular, el culto a la Virgen de Guadalupe y la fiesta en América Latina, son expresiones culturales sintéticas y sincréticas, particulares y únicas. Hablan de nuestro ser (ontología), de una manera de conocer (epistemología), y de una manera de hacer estética latinoamericana diferenciada de otras culturas, pero perteneciente a las grandes matrices 
culturales de Occidente. Y eso el Maestro Alejandro Serrano Caldera, lo sabe mejor que nadie y así nos lo ha enseñado.

No quiero concluir esta breve exposición sin dejar de hacer por lo menos mención a la dimensión axiológica en la filosofía del Maestro Serrano Caldera y vislumbrar como un chispazo de relámpago la rica veta de la paz en su obra.

La angustia del ser humano ante el equilibrio de terror existente en la guerra fría y ante el horror de las guerras y violencias que le han sucedido, bien los expresa Serrano Caldera en este par de párrafos citados a continuación:

Es necesario dar un salto cualitativo y pasar del equilibrio del terror que nace del armamento (símiles mísiles) al equilibrio que garantiza el derecho internacional. En el futuro inmediato, éste está llamado a ser el punto de apoyo de la comunidad mundial, la única alternativa ante el horror de la posibilidad de la hecatombe nuclear, o de la hecatombe cotidiana de la guerra, la muerte y la miseria.

Los elementos del futuro de América Latina y el mundo están ahí, frente a nuestros ojos. De nosotros depende que el mundo sea una hoguera o un lugar dignamente habitable. Para que esto último sea posible, es absolutamente necesario un cambio cualitativo de los valores y de las conductas. ( $(5-6$, p. 233, 12. La historia como reafirmación o como destrucción, $U$ ).

Ante la profunda crisis económica, medioambiental, política, axiológica (valores) y espiritual que vivimos en nuestro planeta es preciso restablecer los equilibrios y avanzar hacia un futuro de sanidad ambiental, de crecimiento económico equitativo, de sistemas políticos democráticos y libertarios, de valores éticos y supremos como la justicia, la paz, la libertad y el amor.

Tomando como fundamento todos los elementos mencionados anteriormente, es que nos atrevemos a plantear a la cultura de paz como la síntesis cultural y la utopía a construir en nuestra región para compartirla con el mundo. No porque los latinoamericanos estemos predestinados para esta misión, ni porque nos lo haya revelado una energía superior y trascendente, sino sencillamente, porque nuestra historia y nuestro pensamiento filosófico, donde brilla con luz propia la obra del Doctor Alejandro Serrano Caldera, nos aportan elementos considerables en el proceso de construcción de una cultura de paz que obviamente significa vivir en un mundo mejor.

Gracias Maestro Alejandro por su espléndida vida y por su fructífera obra.

\section{Bibliografía:}

1. Serrano Caldera, Alejandro: Obras Volumen III América Latina ante la razón filosófic - Escritos sobre el pensamiento, la política y la cultura nicaragüense, Edición de Pablo Kraudy, Publicada por CNUAECID-Hispamer, Managua, 2011.

2. Lévi Strauss, Claude: El pensamiento salvaje, FCE, México D.F. 1962.

3. Lovo, Anastasio: Cultura de paz-Historia, epistemología y textos-, Editorial Nos-Otros UPOLI, Managua, 2012. 